Transport and Telecommunication, 2013, Volume 14, No 2, 93-101

Transport and Telecommunication Institute, Lomonosova 1, Riga, LV-1019, Latvia

DOI 10.2478/ttj-2013-0008

\title{
THEORETICAL INVESTIGATION OF SUPPLY CHAIN SERVICE LEVEL IN HUNGARY AND POLAND
}

\author{
Stanisław Borkowski ${ }^{1}$, Renata Stasiak-Betlejewska ${ }^{2}$, Adam Torok ${ }^{3}$ \\ ${ }^{1}$ Institute of Production Engineering, Faculty of Management, Częstochowa University of Technology \\ Al. Armii Krajowej 19B, 42-200 Częstochowa, Poland \\ E-mail: bork@zim.pcz.pl \\ ${ }^{2}$ Institute of Production Engineering, Faculty of Management, Częstochowa University of Technology \\ Al. Armii Krajowej 19B, 42-200 Częstochowa, Poland \\ E-mail: renatastasiak@wp.pl \\ ${ }^{3}$ Budapest Univeristy of Technology and Economics, Department of Transport Economics, \\ Faculty of Transport Engineering and Vehicle Engineering \\ Stoczek u. 2. 1111 Budapest, Hungary \\ E-mail:atorok@kgazd.bme.hu
}

The article presents research and analysis in the enterprises of logistics chains. The paper demonstrates the main findings of the investigation. Theoretical investigation has been done in order to measure the relations between enterprises, suppliers and customers. Whatever the nature of the logistics chain is, the problem for the company remains how to deal with suppliers. This paper focuses on the assessment of supply chains and forecasting influence possibilities. The guidelines describe supplier selection. The methodology presented allows the assessment of suppliers.

Keywords: supply chains, suppliers, assessment

\section{Introduction}

Logistics in the global economy is a rapidly growing scientific discipline (Fig. 1).

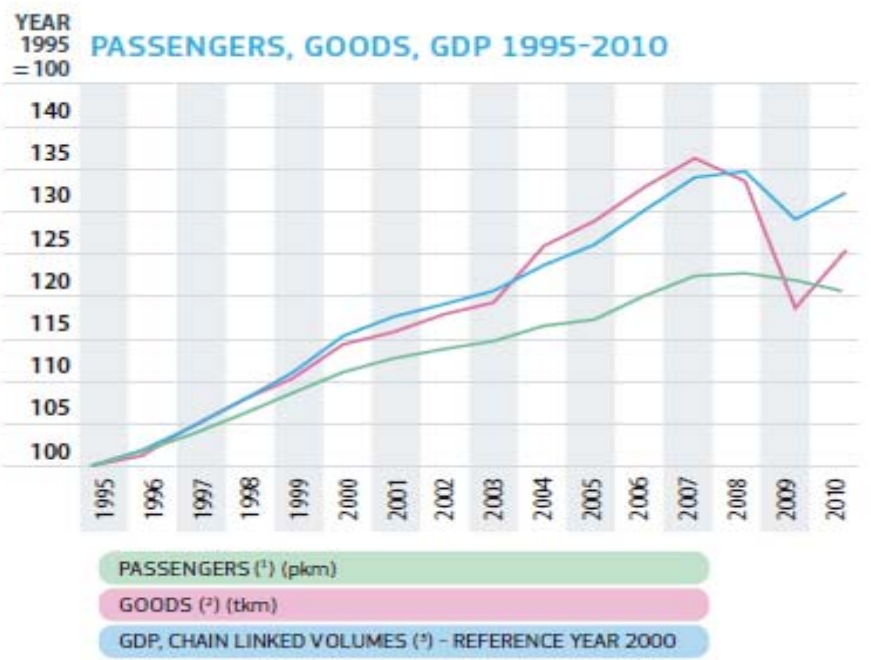

Figure 1. Goods and Passenger Transport Performances and Changes of GDP in EU

(source: EU transport in figures http://ec.europa.eu/transport/publications/statistics/doc/2012/pocketbook2012.pdf)

Such an intensive logistics development caused various problems with regard to its structure, volume [1]. Logistics has become an important component of manufacturing. The logistics in the global 
economy is rapidly growing scientific discipline. It can be accused for a certain possessiveness of research areas. Supply chain management decisions are made at an enterprise level that determines benefits and efficiencies of the supply chain. These are business decisions that compare the costs and benefits of manufacturing a product or product component against purchasing it. If the purchase price is higher than what it would cost the manufacturer to make it, or if the manufacturer has excess capacity that could be used for that product, or the manufacturer's suppliers are unreliable, then the manufacturer may choose to make the product. This assumes the manufacturer has the skills and equipment necessary, access to raw materials, and the ability to meet its own product standards. A company who chooses to make rather than buy is at risk of losing alternative sources, design flexibility, and access to technological innovations. There has been a rapid development of logistics centres in Hungary (Fig. 2).

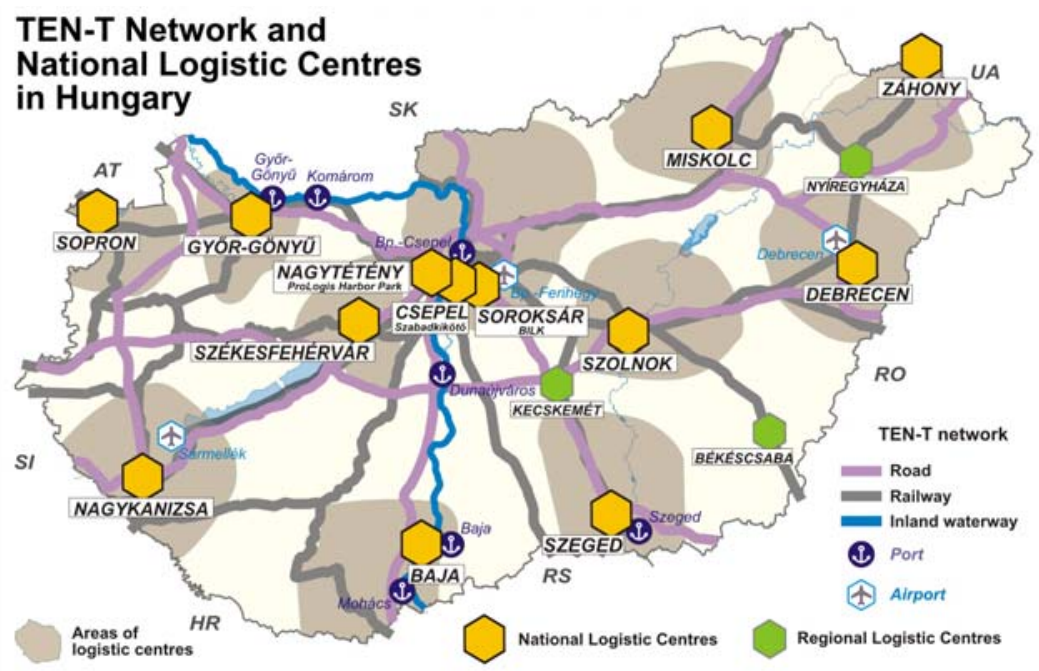

Figure 2. TEN-T Networks and National Logistic Centres in Hungary (source: KTI - Institute for Transport Sciences)

The well-known logistics system "just in time" [2] was adapted to a limited extent in Polish conditions, probably due to the road infrastructure. Strategic supply chain management decisions are made at an enterprise level that determine benefits and efficiencies of the supply chain. These are business decisions that compare the costs and benefits of manufacturing a product or product component against purchasing it. If the purchase price is higher than what it would cost the manufacturer to make it, or if the manufacturer has excess capacity that could be used for that product, or the manufacturer's suppliers are unreliable, then the manufacturer may choose to make the product. This assumes the manufacturer has the skills and equipment necessary, access to raw materials, and the ability to meet those own product standards. A company which chooses to make rather than buy is at risk of losing alternative sources, design flexibility, and access to technological innovations [3]. The Just in Time or Just in Time method creates the movement of material to a specific location at the required time, i.e. just before the material is needed in the manufacturing process. The technique works when each operation is closely synchronized with subsequent ones to make that operation possible. Just In Time is a method of inventory control that brings material into the production process, warehouse or to the customer just in time to be used, that reduces the need to store excessive levels of material in the warehouse [4]. The Just in time logistics system was adapted to a limited extent in Polish and Hungarian conditions, probably due to the lack of road infrastructure. In Poland, the Just In Time system of providing parts for various types of companies works where assembly is a basic operation. The service level of logistics chain supporting enterprises is the research object of this paper. Suppliers are important elements of this chain [5]. The supplier must be in symbiosis with the manufacturer. Supplier selection can be implemented in different ways. The scientific basis for supplier selection can be described as Toyota's eleventh principle: respect wide network of partners and suppliers, throwing them challenges and help them to improve themselves [6]. Toyota is more than a theory. It is committed to trying to improve suppliers' systems as a part of their own manufacturing system and show them how to improve the service level. For example, production systems can facilitates the work of suppliers. Suppliers of many industries (e.g. automotive industry) consistently prove to be the best customer, but also a difficult client. This means that the Manufacturer sets very high standards of excellence and expects all those partners to comply. It requires a continuous 
process of improvement on the supplier's side. Development of suppliers is based on a series of stringent targets that must be achieved. However, this represents a solid base for suppliers whose can thus obtain the respect of competitors and other customers. The solution is taking care of a partner, who has the ability to ensure constant quality in the circulating flow, shipping products to reach the first assembly point, and eventually to customers, just in time. The handling warehouse in this system is designed in accordance with the workflows, and the employees are committed to continuous improvement [7]. Visual indicators and devices to prevent faults are widespread in the sector to ensure the quality. Quality and reliability in the process for the lowest possible cost is the most important goal. There is a need for strict coordination of the various parts between suppliers, warehouse handling and assembly plants. The flow of parts from manufacturers to assembly plants is carefully tuned.

\section{Methodology}

Currently the logistics of car manufacturing is undergoing important changes. Several powerful trends have appeared in the market recently. On the one hand, customer needs became very heterogeneous; on the other hand, the automotive industry has reached a point where the deciding part of their sales revenues and, most importantly, of their profit comes from the so-called 'downstream' activities (financing, repair, insurance, second-hand car trading). It represents those areas, in which the number of interactions with customers and consequently, also the chance of developing customer loyalty are very significant [8]. Today, buyers want to express their own personality through the product they purchase. The number of legally independent car manufacturers is strongly decreasing, while there were 62 in 1960, in 1970 there were 36, in 1990 there were 21 and in 2005 there were only 14. This trend has continued despite the ever-prevailing trend in motorization, and the environmental problems it has brought about, necessitating new ways of demand management [9].

For this reason automakers are going to restrict their production to modules, subassemblies, and technologies, which are crucial to building the automobile brand image, thus further enhancing the brand profile. The automakers must organise these value-creating activities in-house, without any delay. An important consequence of all these factors are the reinterpretation of the role of the players in the automotive production structure: the automakers are going to be high-tech-brand dealers, while the suppliers assume step-by-step all the 'non-branding' tasks. As automakers cannot increase their market prices because of the tough competition, there is only one possibility left: they want to solve their cost problems through enforcing a continuous decrease in suppliers' prices. Therefore, the profitability of many suppliers is declining. This subpar profitability will lead to a situation in which the concentration of the supplier sector takes larger and larger dimensions; in other words, the number of suppliers whose are independent from concerns is on the decrease. A clear tendency is visible: all suppliers of the automotive industry are under an enormous price pressure and under a constraint to "get placed" in the supplier pyramid and this tendency is going to become even stronger in the next few years. The life cycle of a car has shortened (Fig. 3) but the number of different classes has grown. For instance in 1950, 4 million vehicles were sold in 13 segments in Europe. In 2002, 15 million vehicles were sold in 18 segments in Europe.

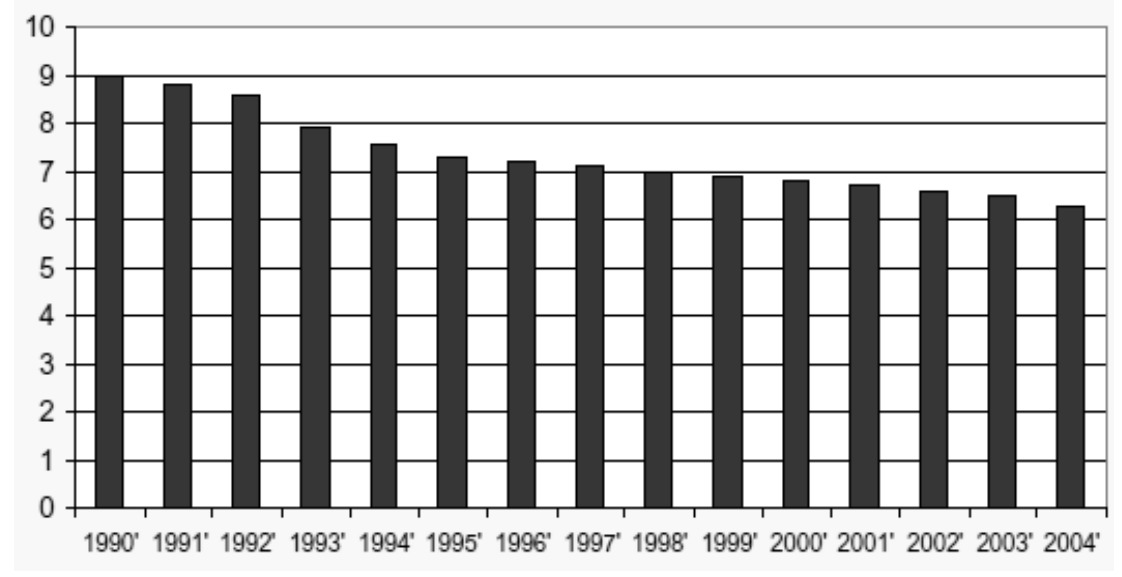

Figure 3. Development of car lifecycle (source: [8]) 
Today, common platforms are used in auto manufacturing. These common platforms then get the brand special marketing signs. For instance, GM and Chevrolet are using average platforms.

An innovative researching method has been developed by the Institute of Production Engineering at Częstochowa University of Technology. We can assume that the described methodology is a summary of factors, which can be divided into two groups:

- Problems that influence only employees,

- Problems that influence processes management.

As the selection of suppliers is the responsibility of managers, they were asked to answer the following questions:

During supplier/subcontractor selection, your company is guided by the following factors: in the box, please type 1, 2, 3, 4, 5, 6, 7 (7-the most important factor and 1-less important factor) [10]:

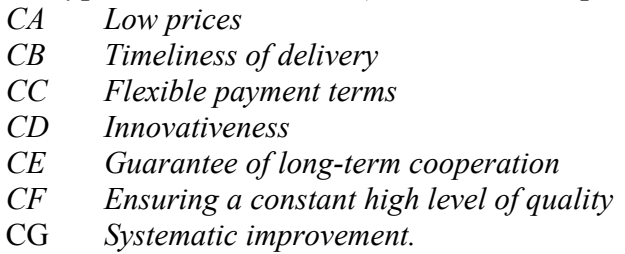

There are a few basic processes in the logistics chain, such as production management, supplies management, demand management, orders management, and purchase. All factors mentioned above concern logistics chains in the process of their improvement with regard of categories like: time, flexibility in supply condition changes, and quality in supporting proper service quality. The results were the object of the static analysis [11]. An important element of the study is to quantify the results describing Toyota's eleventh principle based on the Pareto-Lorenz diagram [12]. The pie charts were used for the presentation of the validity structure of factors. Correlation graphs are an important element of the research elaboration. Features of respondents/managers are the independent variables of: gender, education, age, seniority, mobility, mode of employment. Research findings were elaborated statistically by applying: average, variance, standard deviation, coefficient of variation, skewness, and kurtosis. See in results (Fig. 4).

\section{Results}

After the analysis of the findings, the general summary of the results obtained was created in the form of Table 1. The intersection of rows and columns gives the number of answers (Table 1).

Table 1. Results of questionnaires

\begin{tabular}{|c|c|c|c|c|c|c|c|}
\hline \multirow{2}{*}{$\begin{array}{c}\text { Evaluatio } \\
\mathbf{n}\end{array}$} & \multicolumn{7}{|c|}{ Indicating the factors' } \\
\cline { 2 - 8 } & CA & CB & CC & CD & CE & CF & CG \\
\hline $\mathbf{1}$ & 2 & 1 & 2 & 1 & 1 & 4 & 1 \\
\hline $\mathbf{2}$ & 2 & 3 & 1 & 1 & 2 & 1 & 2 \\
\hline $\mathbf{3}$ & 1 & 2 & 3 & 3 & 1 & 2 & 0 \\
\hline $\mathbf{4}$ & 2 & 1 & 1 & 1 & 1 & 1 & 5 \\
\hline $\mathbf{5}$ & 4 & 0 & 3 & 1 & 1 & 1 & 2 \\
\hline $\mathbf{6}$ & 0 & 3 & 1 & 3 & 3 & 1 & 1 \\
\hline $\mathbf{7}$ & 1 & 2 & 1 & 2 & 3 & 2 & 1 \\
\hline
\end{tabular}

(source: own edition)

In accordance with the statistical analysis requirements [11] calculations for data sets included in Table 1 were done. Statistical analysis was made based on Table 1. Average (Fig. 4a), variance (Fig. 4b), standard deviation (Fig. 4c), coefficient of variation (Fig. 4d), skewness (Fig. 4e), excess coefficients (Fig. 4f) were calculated based on the columns of Table 1. In statistics and probability theory, standard deviation shows how much variation or "dispersion" exists from the average (mean, or expected value). A low standard deviation indicates that the data points tend to be very close to the mean, whereas high standard deviation indicates that the data points are spread out over a large range of values. Skewness is a measure of the degree of asymmetry of a distribution. If the left tail (tail at small end of the distribution) is more pronounced than the right tail (tail at the large end of the distribution), the function is said to have 
negative skewness. If the reverse is true, it has positive skewness. If the two are equal, it has zero skewness.
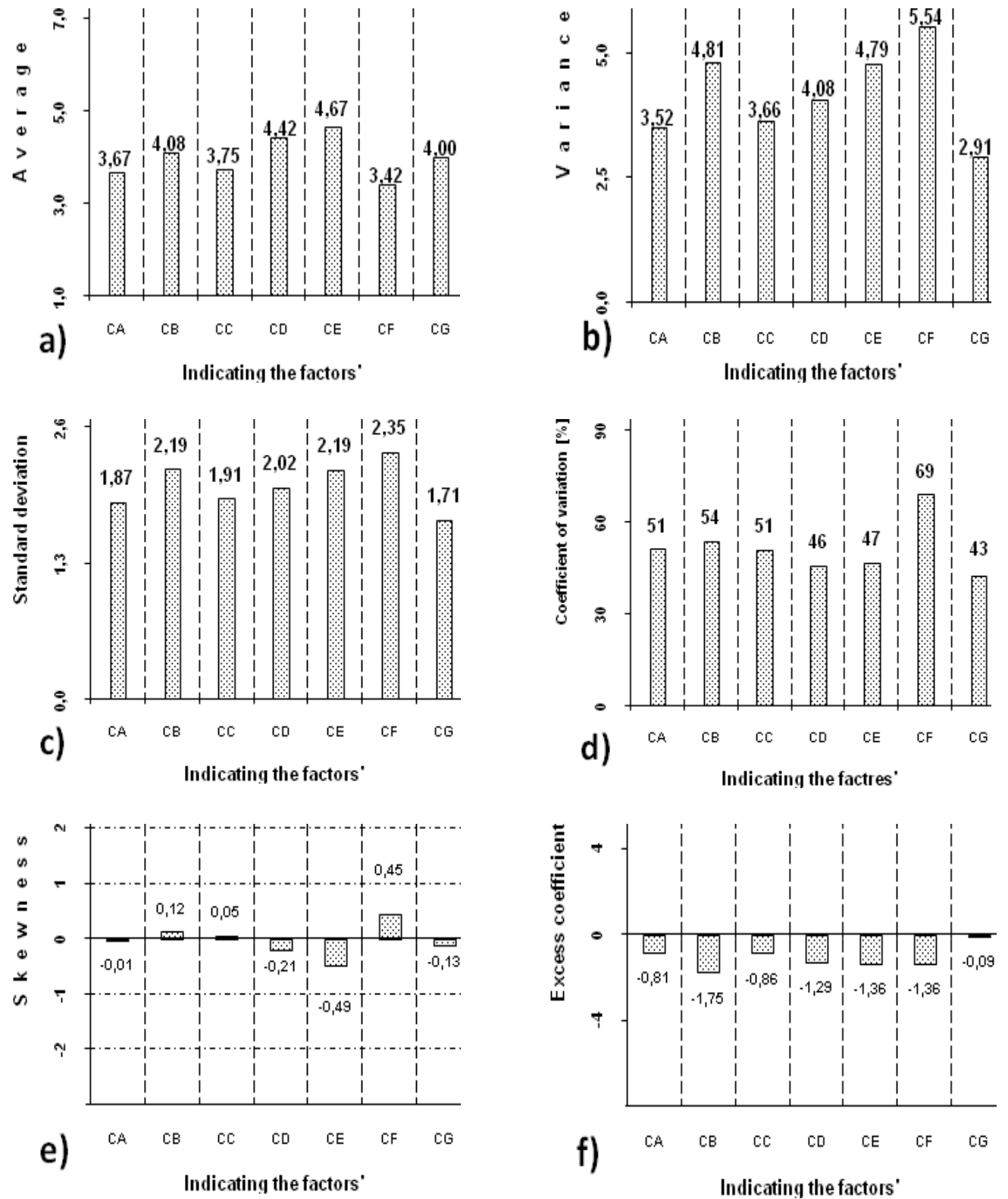

Figure 4. Result of statistical analysis: a) average, b) standard deviation, c) variance, d) variation coefficient, e) skewness, f) excess coefficients (source: own edition)

\section{Analysis}

Mentioned statistical measures were calculated on the basis of the MS-Excel programme 2007. Graphic presentation is authorship elaboration. Presented data were shown in the authorship way, where average are compared with results mentioned with regard to other statistical measures. It was noted that the factor guarantee of long-term cooperation (CE) obtained the highest arithmetic mean. Based on the classic character and values of the asymmetry coefficient (skewness), it can be found (Fig. 4e) that in three cases, - timeliness of delivery (CB), flexible payment terms (CC) and ensuring consistent high level of quality (CF) - we obtained right-sided skewness of distributions. The other collections show left-side bias. Figure 4 shows obtained results in graphical way in the form of a Pareto-Lorenz diagram by the number of the individual evaluation of a factor compared to the total amount of answers in the row (Table 1). The highest accumulated value was obtained by the following factors: 
- $\quad$ Evaluation 1 - least important factor: ensuring a constant high level of quality $(\mathrm{CF})$,

- Evaluation 2: timeliness of delivery (CB),

- Evaluation 3: flexibility payment terms payment (CC),

- $\quad$ Evaluation 4 - medium factor: systematic improvement of suppliers (CG),

- Evaluation 5: low prices (CA),

- $\quad$ Evaluation 6: timeliness of delivery (CB),

- $\quad$ Evaluation 7 - most important factor: guarantee long-term cooperation (CE).
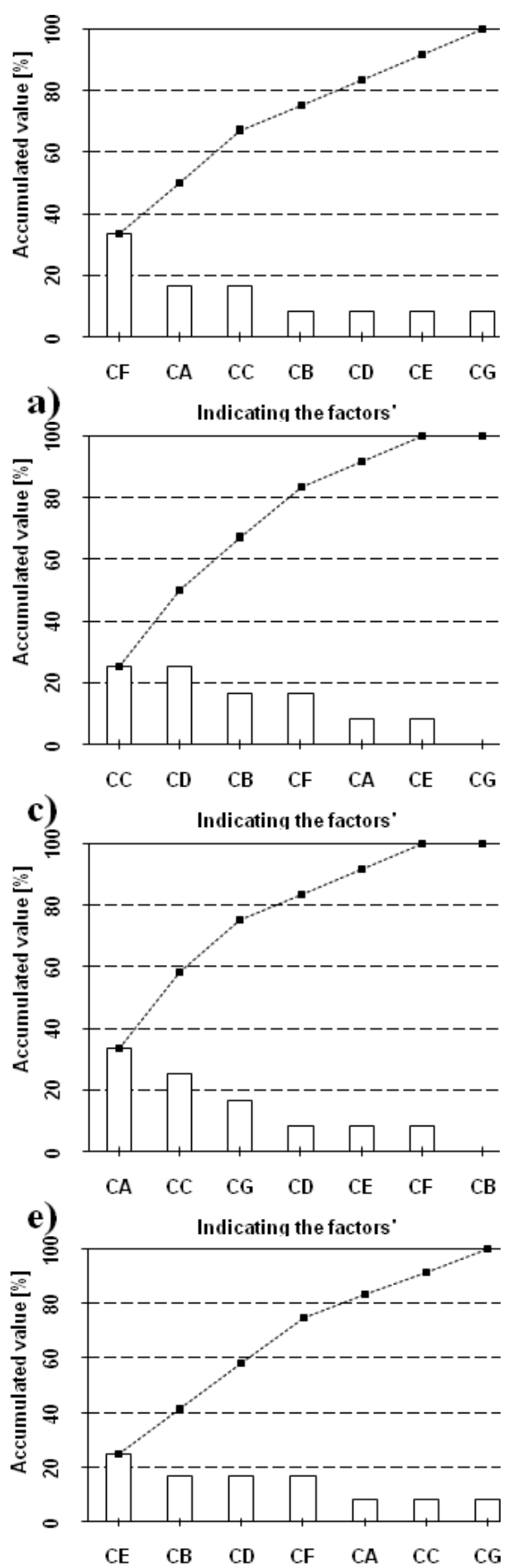

g)

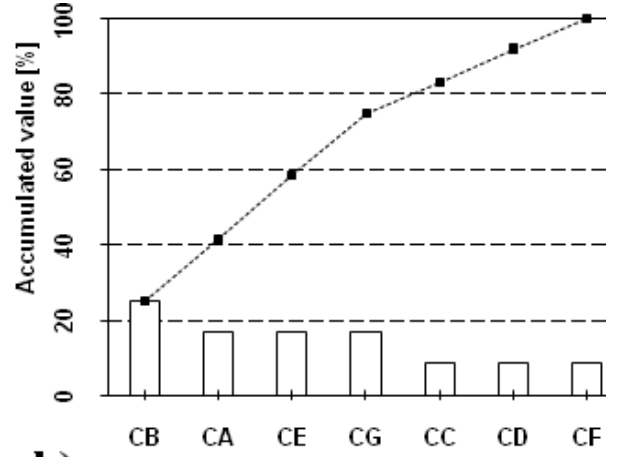

b)
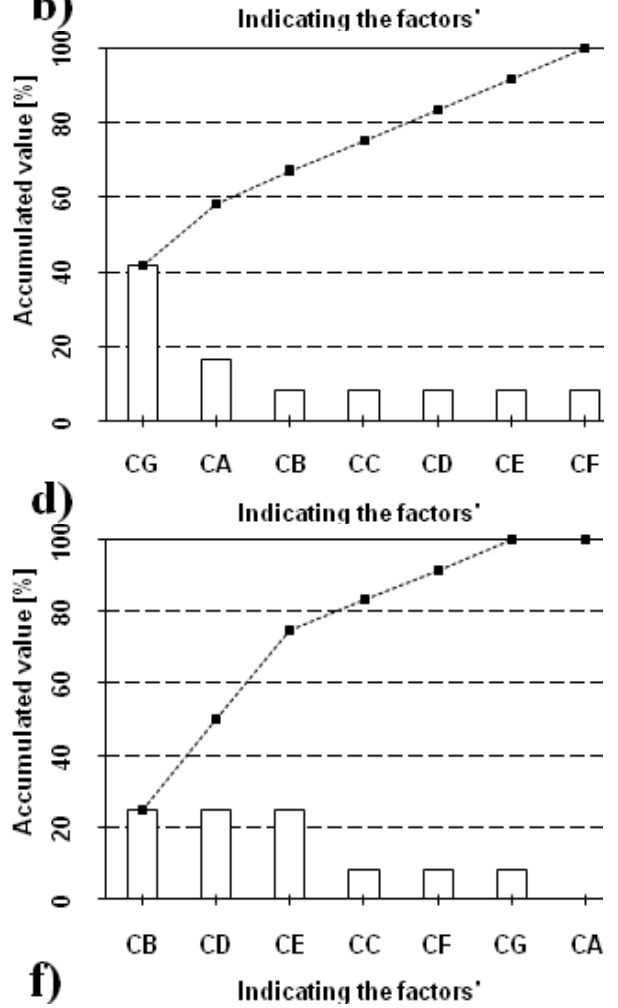

f)

Figure 4. Pareto-Lorenz diagrams of the factors' importance: a) „1”, b) ,2”, c) „3”, d) „4”, e) ,5”, f) „6”, g) ,7” (source: own edition) 
Nota bene, that the factor - a guarantee of long-term relationships with suppliers - is the most important element in the choice of suppliers. During the current study, the existence of an additional factor was also highlighted that determines the validity of factors. There is a further factor, which are obviously the personal traits of respondents. It was found (Fig. 5), that except for the mode of employment; all other features of respondents (e.g. gender, education, age, seniority, mobility) have influenced the results of the factor evaluation, although with varying degrees of probability.
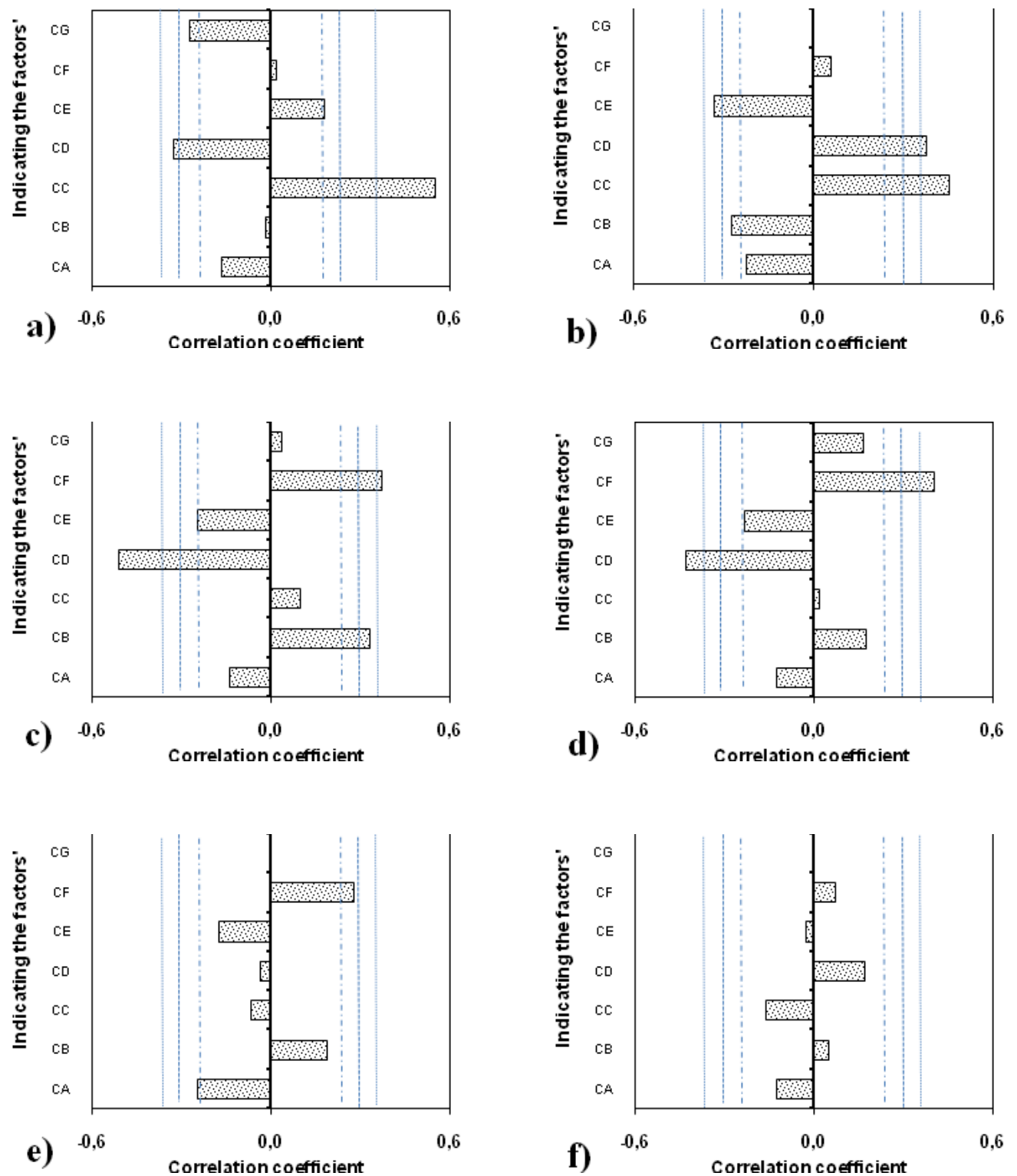

Figure 5. Correlation graphs of evaluations depending on the respondent features:

a) gender, b) education, c) age, d) work experience, e) mobility, f) mode of the employment. $\alpha=0.2$ (internal lines), $\alpha=0.1$ (central lines), $\alpha=0.05$ (external lines)

(source: own edition)

For the probability level (95\%), there is a correlation between respondents' features and evaluations (gender -1 , education -2 , age -2 , work experience -2 . Lower probability requirements (to $80 \%$ ) obviously cause the correlations to increase, and gender affects the evaluations results for four factors, such as: education -4 , age -4 , work experience -3 , mobility -2 . The factors for which evaluation is the most dependent on respondent features are the following: flexibility payment terms (CC), suppliers' innovativeness (CD) and ensuring the constant level of quality (CF) - for all cases per two features. It should be noted that the proposed research methodology has helped reveal the specificity of the selection of specific suppliers. 


\section{Conclusions}

As it is well known, logistics in the global economy is rapidly growing. Logistics have become an important component of manufacturing. If the production cost is higher than the price of purchase or the marginal benefit in the production is very low. The company would outsource the production phase. That is the current tendency in automotive industry. The company which chooses to manufacture rather than buy is at risk of losing alternative sources, design flexibility, and access to technological innovations. For instance, production systems can facilitate the work of suppliers and vice versa. Suppliers of many industries (mostly the automotive industry) consistently prove to be the best customer, but also a difficult client. This means that the Manufacturer sets very high standards of excellence and expects all theirs partners to comply. It requires a continuous process innovation on the supplier side. Customer needs become very heterogeneous; on the other hand, the automotive industry has reached a point where the deciding part of their sales revenues and, most importantly, of their profit comes from the so-called 'downstream' activities (financing, repair, insurance, second-hand car trading). Nowadays automakers will not be able to increase their market prices further because of the tough competition. Therefore, the profitability of many suppliers is declining. This subpar profitability is going to lead to a situation where the concentration of the supplier sector takes larger and larger dimensions; in other words, the number of suppliers that are independent from concerns is going down. That is why authors have investigated suppliers and found that the most important parameters in supplier choice were the factor of guarantee of long-term cooperation (CE). Timeliness of delivery (CB), flexible payment terms (CC) and ensuring consistent high level of quality $(\mathrm{CF})$ were also found as significant parameters.

\section{Acknowledgement}

This work is connected to the scientific program of the "Improving quality of processes, products and services" BW 615/201/07. This project is supported by the Polish Ministry of Science and Higher Education. This article presents as well research results obtained in the BOST research supported also by the Visegrad Fund in the small grant "Toyotarity in the context of European enterprises" (Project ID: small grant11020163 in 2010-2011 and small grant 11130004 in 2011-2012). BOST method is protected by law regulations of the intellectual property protection. The name and its structure is protected by the principle of first date (AAK Kancelaria Patentowa. Częstochowa. 2012). Authors are grateful for the support of Bólyai János scholarship of HAS. Authors are further on grateful for the valuable advice of Ms. Veronika MOHACSI.

\section{References}

1. Markovits-Somogyi, Rita, Gecse, Gergely, Bokor, Zoltán. (2011). Basic efficiency measurement of Hungarian logistics centres using data envelopment analysis. Periodica Polytechnica-Social and Management Sciences, 19(2), 97-101.

2. Skowronek, Cz., Sarjusz-Zwolski, Z. (2003). Logistyka w przedsiębiorstwie. Warszawa: PWE.

3. Christopher, M. (1992). Logistics and Supply Chain Management: Creating Value-Adding Networks (p. 299). Pearson Education Limited.

4. Afshin Mansouria, S., Galleara, David, Askariazadb, Mohammad H. (2012). Decision Support for Build-to-Order Supply Chain Management through Multi-objective Optimization. International Journal of Production Economics, 135(1), 24-36.

5. http://pdn.sciencedirect.com/science?_ob=MiamiImageURL\&_cid=271692\&_user=8472068\&_pii= S0925527310004457\&_check=y\&_origin=browseVolIssue\&_zone $=$ rsitt list_item\&_coverDate $=201$

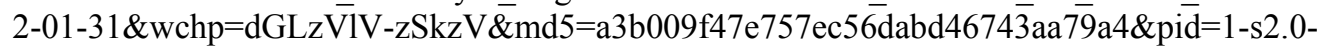
S0925527310004457-main.pdf\&sqtrkid $=0.8321587404242957$

6. Markovist-Somogyi, Rita, Nagy, Zoltán, Török, Ádám. (2009). Change Management for the Greening of Supply Chains. Acta Technica Jaurinensis, 2(3), 393-402.

7. http://journal.sze.hu//downloadmanager/download/nohtml/1/id/5155/m/4319

8. Rother, M. (2011). Toyota Kata (pp. 20-31). Wrocław: Publisher Lean Enterprise Institute Polska.

9. Borkowski, S., Rosak-Szyrocka, J. (2011). Estimation Director's Features Basis on Twelve Golden Principles. Chapter 5. In Scientific Elaboration by Stanisław Borkowski, Renata Stasiak-Betlejewska (Eds.), Human Potential Management in a Company. Manager Features: Monograph (pp. 93-113). Zagreb: Publish. Damir Jelačić. 
10. Karlin, J. (2004). Defining The Lean Logistics Learning Enterprise: Examples from Toyota's North American Supply Chain. A dissertation submitted in partial fulfilment of the requirements for the degree of Doctor of Philosophy (Industrial and Operations Engineering). The University of Michigan.

11. Csaba, Svéhlik. (2005). Challenges and Trends in the Global Automotive Manufacturing Structure. PhD Dissertation, Sopron.

12. www.nyme.hu/fileadmin/dokumentumok/ktk/Kepzes_doktori/2005/2005_SvehlikCsaba_d.pdf)

13. Szendrő, Gábor. (2011). Congestion charging in Budapest - a comparison with existing systems. Periodica Polytechnica Transportation Engineering, 39(2), 99-103.

14. (web: http://www.pp.bme.hu/tr/2011_2/pdf/tr2011_2_09.pdf)

15. Pułaska-Turyna, B. (2008). Statistics for Economists (pp. 221-231). [Statystyka Dla Ekonomistów]. Warszawa: Difin.

16. Borkowski, S. (2004). Quality level management [Mierzenie Poziomu Jakości]. Sosnowiec, Poland: Publisher Wyższa Szkoła Zarządzania I Marketingu W Sosnowcu. 